\title{
Sobre o regime de visualidade racializado e a violência da imageria racista: notas para os estudos da imagem
}

Francielly Rocha Dossin"

Resumo: $\mathrm{O}$ presente artigo tem como objetivo realizar uma investigação sobre os modos de funcionamento da representação produzida pela imagem, sobretudo sobre a representação histórica racista. Para tanto, questionamos a pretensa "transparência" da imagem e interrogamos o caráter violento da imageria racista, assim como as possibilidades de desconstrução dessa visualidade racializada. Palavras-chave: Estudos da imagem. História da imagem. Regime de visualidade racializado. Imageria racista.

If the body is the site of disgust or affect because of its phenotype or color, this is also only because it is part of a broad iconographic history that serves as a reservoir of circulating signs for this purpose. Jeniffer Gonzaléz

A escrita é só metade da história, a outra metade, às vezes a mais importante, é a imagem.

Teju Cole

"Doutora em História pela Universidade Federal de Santa Catarina (UFSC). E-mail: frandossin@gmail.com

Anos 90, Porto Alegre, v. 25, n. 48, p. 351-377, dez. 2018 
Sobre o regime de visualidade racializado e a violência da imageria...

\section{Imageria para se pensar as imagens em sua coisalidade}

A imagem é pensamento, tanto quanto aquele que se exprime por palavras; ela é, sempre, reflexão sobre o mundo e os homens.

Tzvetan Todorov

O uso de imagens como fonte de informação não é uma novidade. A História há muito se utiliza, de uma forma ou de outra, de fontes visuais. Entretanto, sabemos que a tradição Ocidental sempre a teve sob suspeição. A imagem não corresponde à noção tradicional de documento, trazendo assim problemas específicos ao trabalho do historiador que opera com fontes visuais. Mais do que isso, a História não tem pensado apenas a imagem como fonte, mas também a relação da imagem com a construção da História e do fazer do historiador. Para os historiadores, uma imagem pode ser evidência e pode ser história ela mesma. Uma imagem pode ser fonte ao mesmo tempo em que seus usos e significações podem revelar ações e agenciamentos.

Para o historiador Ulpiano Bezerra de Meneses, é necessário que a história tome as "coisas visuais" como "objetos" e não apenas como "conteúdo". Pensar em termos de "coisalidade" é pensar a imagem em sua completude. Para isso, temos de observar o circuito que ela percorre, isto é, feitura (ou produção), circulação, apreciação, consumo e apropriação. A tarefa do historiador que lida com "coisas visuais" é compreender a historicidade das imagens em sua coisalidade. Ainda que a completude - refiro-me ao conhecimento de toda a trajetória de uma imagem, da produção à apropriação seja impossível de alcançar, ela deve ser um alvo no horizonte, tal qual a objetividade. A completude pode ser almejada sem ignorar as complexidades das visualidades que constituem regimes. Os regimes de visualidade são frutos da história ao mesmo tempo em que "fazem" história.

Quando entramos em contato com a literatura de língua inglesa e francesa sobre teorias da imagem, uma dificuldade surge: a presença do vocábulo imagery. Em inglês imagery e em francês imagerie, são termos cujo correlato em português não é facilmente traduzido, mas cujo significado pode nos auxiliar a privilegiar as

Anos 90, Porto Alegre, v. 25, n. 48, p. 351-377, dez. 2018 
imagens em sua materialidade. O dicionário Le Nouveau Petit Robert dá à imagerie três sentidos. O primeiro deles, ligado à fabricação e ao comércio de imagens; o segundo, relacionado a um conjunto de imagens que tenham a mesma origem (como imagerie d'Épinal), ou que tenham uma mesma inspiração (como imagerie populaire, imagerie romantique) e, por último, relativo a um conjunto de imagens obtidas a partir de uma mesma técnica (como imagerie médicale, imagerie moléculaire, imagerie astronomique).

$\mathrm{Na}$ língua inglesa, observamos que o termo francês imagerie ora corresponde ao termo imagery, ora ao termo imaging. No dicionário de língua inglesa Webster's Encyclopedic Unabridged Dictionary of English Language, encontramos o verbete imagery, cuja definição privilegia o aspecto mental da formação de imagem. Nele, o verbete se define como "a formação de imagens mentais", "imaginário coletivo", "imagens retóricas", "descrição figurativa ou ilustração" e "imagem pictórica", sendo que apenas este último sentido acena para uma materialidade da imagem. Entretanto, o dicionário The Shorter Oxford English Dictionary, além do sentido ligado à "imagem mental", também oferece o sentido material, definindo o termo como relativo às estampas, à estatuária, à pintura $\mathrm{e}$ à idolatria. O Compact Oxford English apresenta três sentidos para Imagery, o primeiro referindo-se à criação de imagens mentais pela linguagem, o segundo a "simbolismo visual" e o último o define como "imagens visuais como um todo" (visual images as a whole). Vemos que os sentidos são um pouco confusos e que muitas vezes parecem se assemelhar a termos como imaginário, imagético, imaginação, imaginística.

$\mathrm{Na}$ literatura que trata de estudos de imagens e cultura material, é frequente a utilização do termo inglês imagery e do termo francês imagerie para se relacionar com algum aspecto material, de produção ou circulação de imagens que compartilham a mesma origem, temática ou técnica de feitura. Imagerie e imagery portam a capacidade de definir um conjunto de imagens abarcando sua materialidade e agenciamentos. No português, imagerie é traduzido de diferentes maneiras. Muitas vezes traduz-se por "imagens", simplesmente. Embora não seja possível encontrar esse verbete no Sistema de busca do Vocabulário Ortográfico da Língua Portuguesa 
(VOLP), feito pela Academia Brasileira de Letras (ABL), tampouco no Dicionário Houaiss da Língua Portuguesa. Encontramos o verbete imageria no dicionário Novo Aurélio, que também o define como construção literária ou retórica, textualmente: "Imageria: Meio expressivo, ger. Individual, concreto ou figurado, us. por um escritor em certos trechos onde deseja obter um efeito específico (como recurso emocional especial, ou cadeia de associações intelectuais)."

Em uma tese de 2011, da área de comunicação e informação, Ana Paula Penkala utiliza o termo aportuguesado imageria para se referir a um padrão estético ou a uma recorrência técnica no audiovisual contemporâneo. $\mathrm{O}$ que ela chama de imageria "[...] é o conjunto de imagens relativas a uma dada coisa" (PENKALA, 2011, p. 18). O termo está atrelado a um determinado imaginário, mas não se confunde com este, pois define sua expressão material, de consumo e apropriação, e não apenas mental. Como afirma Penkala, "[...] a imageria é parte de um imaginário ao mesmo tempo em que é constituída por ele” (2011, p. 21).

Uma dada imageria se relaciona com um imaginário específico, delineada por condições sociais, históricas e de produção. Podemos pensar imageria como um determinado conjunto de imagens que nos oferece um recorte privilegiado para se pensar uma dada problemática ligada aos usos da imagem. Imageria é um corpo de imagens relacionadas com um ou mais elementos, de origem, de tema, de feitura, de temporalidade, de consumo, de uso.

O historiador André Gunthert, por exemplo, desenvolveu o conceito de imagerie auto-référentielle (imageria autorreferencial) ${ }^{2}$ como categoria para pensar a rápida reprodução e apropriação de imagens possibilitadas pelas tecnologias contemporâneas. Segundo ele, imageria

[...] é uma iconografia e é um conceito. É um grupo de imagens que contém certas propriedades dinâmicas. Eu me apoio bastante nas teorias da etnometodologia que levam em conta os desenvolvimentos temporais de um processo, algo que se desenvolve e muda no decorrer do tempo, portanto, na dimensão dinâmica de uma imagerie. É uma iconografia que produz algo e que se transforma ao longo do tempo, 
e que, por conseguinte, tem uma característica particular que podemos identificar e reconhecer, especialmente o seu caráter produtivo e dinâmico. Não há nada de mágico nisso. Trata-se de algo que é concreto e que podemos descrever na história e para a história. É complicado, porque quando há imageries complexas, como são hoje praticamente todas imageries industriais, e é um trabalho grande, numeroso e de grandes equipes, descrever corretamente esses conjuntos que podem incluir várias centenas de milhares de formas (GUNTHERT apud DOSSIN; LEAL, 2015, p. 99).

Utilizando-se do neologismo imageria, podemos falar, por exemplo, em imageria racista, como o blackface, que seriam "coisas visuais” próprias do regime de visualidade racializado.

\section{Blackamoor, sobre o desenvolvimento de uma imageria racista}

É lamentável que perguntas sobre "raça" e representação tenham sido tão regularmente banidas das histórias ortodoxas do juízo estético, gosto e valor cultural do Ocidente.

Paul Gilroy

A imagem do Blackamoor é um exemplo de imageria racista que está inscrito no regime de visualidade racializada, fazendo-se presente na cultura visual e material do Ocidente, sobretudo durante a primeira modernidade 3 . O blackamoor é um gênero de representação manifestado principalmente nas chamadas "artes decorativas", mas com incidências também na joalheria e na pintura, e que se refere a figuras negras, na maioria das vezes masculinas, e em poses de servidão. Sua origem remonta à chamada "reconquista cristã" da Península Ibérica, que só acabou no início da Idade Moderna. A servidão, com a qual é representado, parece um contraponto domestificador à fama de valentia dos mouros africanos. Como nos relata Devisse e Labib, a partir da iconografia espanhola dos combates entre cristãos e muçulmanos, "a iconografia [...] revela o

Anos 90, Porto Alegre, v. 25, n. 48, p. 351-377, dez. 2018 
Sobre o regime de visualidade racializado e a violência da imageria...

lugar dos "mouros negros" nos exércitos da Espanha muçulmana, que se batiam contra os cristãos; no século XII, Ibn 'Abdûn conta-nos, em seu manual Hisba que esses negros eram encontrados na Sevilha almorávida e reputados perigosos" (DEVISSE; LABIB, 1988, p. 739).

As representações de africanos como cavaleiros, reis ou príncipes remontam ao menos às conquistas romanas (STOLS, 2008, p. 234). No entanto, são as cruzadas contra os muçulmanos no Oriente Médio e na Península Ibérica que "[...] familiarizaram os cristãos com a existência de soldados mouros e negros, e fertilizaram tanto a idealização quanto a diabolização de sua valentia guerreira e sensualidade” (STOLS, 2008, p. 234-235). No século XVI, início do tráfico atlântico, as imagens dos mouros negros se popularizam na Europa através do desenvolvimento dessa produção iconográfica que difundiu a figura do negro "como tocheiro, suporte de candelabros, ou de relógios” (STOLS, 2008, p. 250). O mouro negro já era um motivo heráldico desde a Idade Média, quando era normalmente relacionado a figuras como a de São Maurício. Um exemplo é a cabeça de mouro negro presente desde o escudo eclesiástico no brasão do papa emérito Bento XVI à bandeira da Córsega. Como explica Stols, a submissão do negro torna-se tema de pinturas mostrando o batismo e sua entrada na comunidade cristã, como em Le Baptême de l'eunuque éthiopien par l'apôtre et diacre saint Philipe, de Herman Nauwick. O outrora inimigo, ao menos desde as Cruzadas, o selvagem, sanguinário e de pele escura, se materializa no Renascimento europeu como um exótico serviçal, um pajem decorativo.

Stuart Hall (1995, p. 298) mostra como fontes bíblicas e religiosas, narrativas mitológicas e os relatos dos viajantes formaram a fonte das variadas imagens grotescas de "outras" raças que posteriormente se tornaram uma profecia autocumprida ${ }^{4}$, como nos "testemunhos" sobre a realidade de muitas dessas lendas durante a expansão marítima. Essas fontes são as "evidências" que formam os "arquivos" basilares da construção do conhecimento moderno que estruturou noções binárias e hierarquizadas. Como arquivo o autor se refere ao conjunto de obras e conhecimentos acumulados pelo Ocidente.

Anos 90, Porto Alegre, v. 25, n. 48, p. 351-377, dez. 2018 
Esse arquivo da representação racializada na cultura popular do ocidente, para Hall, foi formado em três momentos. O primeiro refere-se ao encontro dos comerciantes europeus com os reinos africanos, fornecendo pessoas escravizadas por, ao menos, três séculos. O segundo refere-se à colonização, que tem na divisão da África o seu ápice; e o terceiro, mais contemporâneo, trata das migrações do sul em direção ao norte, ou seja, dos outrora chamados países de terceiro mundo em direção aos países de primeiro mundo, que se deu posteriormente à Segunda Guerra Mundial. Esses são três momentos importantes na construção do regime racializado de visualidade, de acordo com o sociólogo jamaicano.

$\mathrm{Na}$ Idade Média, a imagem da África era ainda ambígua e misteriosa. Na transição para a Idade Moderna, as pessoas do continente africano passam a ser identificadas com o estado natural e primitivo, em contraste com o mundo civilizado. Depois das narrativas bíblicas, são as evidências etnológicas e científicas que passam a fornecer a base para o racismo. Em um segundo momento, o de colonização da África, produz-se uma explosão de representações exóticas e pitorescas, com a reprodutibilidade técnica há o aumento da capacidade de produção e distribuição dessas imagens. A conquista colonial gera variadas imagens que passam a estampar embalagens de diversos produtos, como sabonetes, cafés, chocolates, cigarros, bebidas, chás, biscoitos e assim por diante. Nesse momento, de circulação cada vez mais global, se comercializa todo tipo de imageria racista, "nenhuma forma de racismo organizado pré-existente tinha sido capaz de alcançar tão larga e tão diferenciadamente uma grande quantidade de gente” (MCCLINTOCK apud HALL, 1997, p. 240).

No Brasil, desde a publicação de "Como se deve escrever a história do Brazil" (1845), de Von Martius, e "História geral do Brasil" (1854), de Francisco Adolfo de Varnhagen, a representância histórica ${ }^{5}$ estabeleceu uma imagem das três raças fundadoras na criação de uma história nacional. Como explica Flores e Melo (2014, p. 46), "[...] a criação da história nacional e o estudo da população do país eram exigências sine qua non no processo de formação do Estado nacional moderno". As questões raciais são incontornáveis para se pensar a história e a cultura brasileira. O "laboratório racial" que se dava no Brasil era observado positivamente por outras nações, 
pois era considerado bem-sucedido se comparado ao que ocorria nos Estados Unidos e na África do Sul. Entretanto, o Brasil desenvolveu formas próprias de manutenção da ordem racial.

Assim, encontramos no Brasil uma vasta gama de imageria racista, a exemplo do personagem Moleque, da revista Semana Ilustrada. Os dezesseis anos que a Revista atuou no Império foram marcados pela presença dos personagens que estampavam a primeira página: Dr. Semana e o Moleque, seu companheiro constante. Moleque é um jovem escravizado, alfabetizado em português e sempre ao lado de seu senhor branco, um personagem com cabeça bastante avantajada, desproporcional ao tamanho do corpo. ${ }^{6}$ Os dois personagens, criação de Henrique Fleiuss, logo se tornaram bastante populares. " "O Moleque, que se caracterizava pelos comentários sempre maliciosos, tratava o Dr. Semana por Nhonhô, vestia-se a caráter, usava libré, como era próprio dos pequenos escravos, que trabalhavam como pajens nas casas das pessoas ricas da Corte. Mais tarde, o dueto foi enriquecido com a criação de um terceiro personagem, dona Negrinha, casada com o Moleque" (SECRETARIA, p. 13).

O próprio termo moleque trata de uma despersonalização do personagem, uma vez que é um termo bastante generalizado, empregado não só para os garotos que atuavam como pajem, mas também para qualquer menino negro. No dicionário Houaiss da língua portuguesa, o verbete moleque descreve desde menino novo de raça negra ou mista, criado à solta, brincalhão, até indivíduo sem maturidade, sem integridade, canalha e diabo. $\mathrm{O}$ termo teria vindo do quimbundu, uma das línguas bantu da atual República de Angola, na qual muleke designava apenas "criança” (SANTIANO-ALMEIDA, 2014). O termo foi registrado no Thesouro da Lingoa Portuguesa (1647), escrito pelo padre jesuíta Bento Pereira (1605-1681), e o significado ali constava como adolescens niger, "adolescente negro" 8 . Assim, o termo que designava em quimbundu apenas criança, torna-se criança negra ou africana ao se aportuguesar (SANTIANO-ALMEIDA, 2014).

As charges, geralmente na capa, mostravam a relação entre senhor e escravo através de uma perspectiva patriarcal. O moleque é uma espécie de pajem, um jovem serviçal, uma versão nacional 
do pajem africano, do mouro negro, do tocheiro. Com a inclusão de dona Negrinha, explicita-se que Moleque não é mais uma criança, apesar de ser representado em tamanho muito menor que seu senhor. Vemos nessas relações, mesmo nas mais "apaziguadas", a forma como o homem negro foi privado dos códigos de masculinidade da época. Responsabilidade, autoridade parental e familiar são suprimidas da vida do homem negro quando ele é eternamente tratado como criança, o que Stuart Hall (1997) considera como uma castração simbólica. As figuras do pajem negro, dos blackamoors e do moleque são sintomáticas dessa relação de supressão.

\section{Sobre a violência da imageria racista}

Conforme mencionado, o regime racializado de representação tem por base um entendimento binário que funciona e opera através das atualizações dos arquivos coloniais. O estereótipo é um exemplo de representação que atende aos propósitos da racialização, funcionando através da simplificação, da redução, do exagero, da essencialização e da naturalização. É uma prática representacional que acontece com a seleção de uma característica apenas, seguida de simplificação e redução, criando uma imagem desproporcionalmente exagerada, que passa a ser percebida como a característica única, essencial e natural de algo ou alguém. Esse é o princípio do estereótipo, que quando pensado em relação às diferenças raciais estabelece representações racializadas.

Como defende Stuart Hall, contestar estereótipos significa então aumentar a diversidade de imagens, ou seja, aumentar a criação e circulação de imagens que deem também outros sentidos, abrindo o campo de significação desse grupo de pessoas. Essa abertura é capaz de engendrar realidades, seja através de novas compreensões em relação ao grupo fixado em um estereótipo, seja como uma possibilidade também diversa de autoidentificação do próprio grupo. Assim, a luta para abertura dos estereótipos é frequentemente uma luta para aumentar a diversidade de identidades as quais os indivíduos podem imaginar possíveis, trata-se da política da imagem.

Anos 90, Porto Alegre, v. 25, n. 48, p. 351-377, dez. 2018 
A exclusão e o fechamento são características que estão na gênese desse processo de representação, pois ao reduzir algo ou alguém a uma só característica, acaba-se excluindo todas as outras características que eles poderiam ter. $\mathrm{O}$ segundo passo se refere à valoração binária, pois nesse regime se divide o "normal" e o "aceitável” do "anormal” e do "inaceitável”, transcrevendo uma pretensa oposição entre o bem e o mal.

Através de um regime representacional ocorre a manutenção do poder, não apenas poder relativo ao monopólio econômico ou da força, mas também do monopólio cultural e simbólico, que significa também o poder de representar alguém ou algo de alguma forma - dentro de um certo regime de representação. Como afirma Hall (1997, p. 258), "estereotipar, em outras palavras, é parte da manutenção da ordem social e simbólica”. As desigualdades formam o grande sintoma da existência de estereótipos, pois onde há grande desigualdade há estereótipos.

Podemos pensar, com Marie-José Mondzain, que o estereótipo, e a "unicidade" de significação que ele porta, trata de um tipo de violência. Entrevistada na ocasião do atentado ao jornal Charlie Hebdo, a pesquisadora foi perguntada se deveríamos renunciar às imagens, ao que responde ser uma questão equivocada: "não é essa a questão: imagens são necessárias”. A questão, para a autora, é a invisibilidade provocada por um só tipo de imagem. "Por toda a história - colonial e em seguida, de imigração - tais rostos eram rostos clandestinos. Eles viajam escondidos. Eles só são descobertos quando mortos. Eles foram atingidos por um contínuo 'não-direito' à imagem" (MONDZAIN, 2015)9.

Para a autora, o triunfo do ocidente cristão impôs não apenas a hegemonia de seu calendário, mas também o reinado da imagem. Isso porque é no cristianismo que a imagem vai ter um papel central, pois ela não é um signo ou um mediador como os outros, mas é aquele que "encarna", aquele que transforma em visível o que não é figurável. A partir daí, toda transmissão passou a ser feita através de imagens.

Para a pesquisadora, a violência define-se como: "[...] uma força mal-empregada ou desmedida cujos excessos de efeitos negativos nós reconhecemos bem, uma vez que afetam a dois dos princípios que 
fundamentam a comunidade: a vida e a liberdade de cada um. A violência implica, então, a existência dos sujeitos" (MONDZAIN, 2002 , p. 22). Assim, a questão seria de saber em que medida as imagens poderiam induzir a desejos de morte e de aniquilação. A filósofa defende que a imagem é capaz de suscitar todos os tipos de sentimento, pois o visível afeta nossos desejos e nossas maneiras de amar e de odiar. A imagem está entre as coisas e as não-coisas, ou seja, entre o referente e a criação deliberada. Só assim poderemos compreender as imagens em toda sua complexidade e em seu paradoxo de deter ao mesmo tempo poderes e insignificâncias, dominações e contrapoderes.

A imagem violenta seria aquela que abole possibilidades diversas de pensamento e impede o julgamento; como na tradição do ícone cristão, que se queria pedagógico e onipresente, ou na imagem publicitária, que segue o mesmo objetivo, onde "[...] a violência do visível não tem outro fundamento que a abolição intencional ou não do pensamento e do julgamento" (MONDZAIN, 2002, p. 54). Daí a violência da imageria racista, que limita reiteradamente um único significado, nos mostrando a importância de se pensar as paixões que as imagens podem provocar. A imagem pode provocar paixões, mas é necessário pensar sua força e sua fragilidade, assim como seus usos, pois o poder desejará sempre controlar o amor e o ódio (MONDZAIN, 2002, p. 65)

A verdadeira violência da imagem é quando ela se torna tirânica, aniquilando a possibilidade de pensamento. Os regimes totalitários foram exímios em criar imagens com o objetivo de gerar um único pensamento e um único sentimento. Entendemos, então, que o perigo se apresenta mais na unicidade de pensamento e de emoção que a imagem carrega, gerada pelos poderes que a engendram. A imagem única impossibilita aos "sem-voz" o direito de representação. O estereótipo, no pensamento de Stuart Hall, pode ser pensado como um tipo de imagem única e violenta da qual fala Mondzain. Para ela, a imagem violenta mata a possibilidade de outras imagens:

Não se trata, em uma política do visível, de contabilizar as vozes, mas de dar à voz o lugar onde ela pode ser ouvida 
Sobre o regime de visualidade racializado e a violência da imageria...

dando ao espectador o lugar a partir do qual ele pode, por sua vez, responder e ser ouvido. A violência do visível é o desaparecimento desses locais e, portanto, a destruição da voz (MONDZAIN, 2002, p. 104).

Dessa forma, defender a imagem passa a ser preservar todas as vozes que devem se fazer figurar. É, portanto, resistir à invisibilidade e a tudo que tenta eliminar a alteridade dos olhares.

\section{Desconstruindo o regime de visualidade racializado}

Para compreender o funcionamento da representação de uma imagem, recorreremos ao trabalho de Louis Marin. Entendendo que o tempo reside no signo, Marin aliou sua análise semiológica à observação dos processos históricos. Outra contribuição do autor francês foi desenvolver uma análise política da representação favorável à resolução da dualidade que cruza o debate sobre representação, como nos antônimos presença e ausência, aparência e essência, referente e simulacro.

Seguindo o pensamento do autor, a representação tem um duplo poder: primeiro o efeito de presentificar algo no lugar da ausência e da morte; o segundo trata do poder de autorização e legitimação. Nas palavras de Marin, "representar [...] é trazer de volta o morto como se estivesse presente e vivo, e é também redobrar o presente e intensificar a presença na instituição de um sujeito de representação" (MARIN, 2009, p. 139). Representação tem uma dupla função: figuração e significação, pois toda representação representa alguma coisa, mas, ao mesmo tempo, toda representação é também uma apresentação representando alguma coisa. A representação cria realidades e as próprias condições de sua existência. Representação e poder ${ }^{11}$ são da mesma natureza. $O$ poder, pensando a partir de Ricoeur (2007, p. 96), tem uma intrínseca relação com a ideologia que procura legitimar a ordem e o poder.

Marin abole também as fronteiras entre imagem e texto, chamando-os de representação narrativa ${ }^{12}$. Como sabemos, a imagem, a representação visual, é polissêmica. Soma-se a essas camadas de 
significados o fato de que as imagens não são apartadas dos textos que as circundam. Os textos transformam as imagens em discurso, modificando-as, tal como a imagem atravessa os textos e os transforma; esse é, segundo Marin, o poder transformador da imagem compreendida como trânsito, mas não só aí reside a eficácia da imagem. O poder da imagem a constitui como autora mesmo. Seu poder reside no duplo sentido do efeito da representação: a presentificação do ausente e a autopresentação. $\mathrm{O}$ afeto do sujeito do olhar completa a potência da imagem, portanto a força reside nesse olhar que estabelece uma relação entre a imagem e o sujeito através dos afetos.

Os conceitos de opacidade e transparência também podem nos ajudar a entender a construção das imagens. Tais noções foram desenvolvidas quando Marin escreveu sobre a pintura do quattrocento ${ }^{13}$ privilegiando a noção de opacidade. Segundo ele, numa pintura pode haver tanto elementos opacos como transparentes, que juntos formam um discurso pictórico, pois ambos subsistem na própria funcionalidade da representação. Os elementos opacos apontam obliquamente para a própria estrutura da representação, tendo assim uma característica autorreflexiva.

Um exemplo emblemático de opacidade é a obra Ceci n'est pas une pipe, de Magritte, uma provocação da tendência de se tomar a imagem por seu referente. ${ }^{14}$ Toda a estratégia de construção da imagem é exibida. Já a transparência pode ser pensada através de le portrait de César. C'est César, inscrição na moeda romana que procurava vivificar Julio César a partir de seu retrato. Transparência e opacidade não são opostos, mas partes da mesma realidade da imagem, de sua relação com o referente e com a construção de si própria como outro referente, sua apresentação.

A transparência, cuja tradição se inaugura no Renascimento com o desenvolvimento da perspectiva, se dá hoje principalmente nas imagens de registro e testemunho como a fotografia, o cinema, a televisão e o vídeo, e se tornou um dos elementos fundamentais de nossa cultura; nela a imagem é percebida como o próprio referente. A transparência é o resultado de uma operação que visa a esconder o aparato que a fabricou e o realismo é seu resultado. Encontramos a noção de transparência na gênese do discurso teórico 
da Renascença em Brunelleschi ou Alberti, através da ideia de que um quadro seria como uma "janela aberta ao mundo" e, para se fazer "janela”, a imagem deve se tornar como um écran entre o espectador e o mundo. Essa noção reforça a ideia de presença da realidade, do real através da imagem, isso porque na transparência a construção da imagem é obliterada.

$\mathrm{O}$ desenvolvimento da perspectiva geométrica e linear e a consciência de personalidade individual e social do artista são dois dos eventos que marcaram a modernidade da arte visual no século XV. A criação da perspectiva permitiu a construção de objetividade da representação, inaugurando a imagem moderna com a transparência representativa ao preço da eliminação de sua opacidade, que é a neutralização dos efeitos reflexivos. Embora a transparência seja o resultado de uma operação que visa a esconder o aparato, o dispositivo nunca é totalmente obliterado, pois sempre há algum traço de sua presença. Como afirma Marin (1992, p. 124-125), “[...] a transparência transitiva, mimética, da representação - representar alguma coisa - se articula a sua opacidade reflexiva - se apresentar”.

A produção de imagens que alimentam a ideia de transparência tem seu ápice na fotografia científica. A fotografia estabeleceu desde seu nascimento um estatuto de verdade, pois seu caráter predominantemente transparente a fez ser tida como evidência por excelência, sendo usada como prova. Mas, como sabemos, toda construção de imagem passa por uma dimensão subjetiva. A forma de gerar transparência é a neutralização da possibilidade de se perceber o aparelho ou o dispositivo de captura da imagem. Assim, à imagem é conferido o poder documental ainda que o real seja organizado na produção de uma verdade. Dessa forma, a transparência influi no consumo e na percepção da imagem como uma prova visual da realidade. Por isso, a transparência acaba formando um olhar ingênuo; a denúncia da transparência, ou seja, apontar os dispositivos e os meios de construção dessa imagem tem um caráter subversivo, pois trata de abalar um estatuto de verdade. A fotografia surge inscrita nessa categoria, ela torna-se importante instrumento científico de produção de evidência, por outro lado, instaura uma completa transformação no campo artístico, que até então lidava 
com questões acerca da mímesis. Em ambos os casos isso ocorreu porque a fotografia fora usada como se fosse o próprio referente.

Portanto, a transparência é também ilusão, porque não só induz a considerá-la no lugar do próprio referente, como esconde todo o mecanismo de criação que a desenvolveu e a envolveu dentro de um regime representacional. Nessa sequência, se relacionarmos com o pensamento de Stuart Hall, questionar o funcionamento do estereótipo é também trazer os aspectos opacos da imagem percebida apenas em seus aspectos preponderantes de transparência, abalando o estatuto de verdade. Esses conceitos também são importantes porque os registros científicos usados no desenvolvimento de teorias racistas são imagens construídas através da ideia de transparência, e, por isso, desconstruir essa imageria passa pela compreensão dos aparatos que a construíram e a forma com que foram percebidas e consumidas.

A cultura material e visual é ainda prenhe de elementos dessa visualidade científica do século XIX. Mas como é possível interrogar essas imagens? Quais seriam os meios possíveis de desconstruir ${ }^{15} \mathrm{O}$ regime de visualidade racializado? Essa sempre foi uma das importantes questões de movimentos, de ativistas e de artistas e intelectuais com propósito antirracista.

O exercício da desconstrução se inscreve no campo da História enquanto disciplina, afinal é na ação dos homens no tempo e na sua produção de representações que os conceitos foram construídos. A História, portanto, é também a área que pode nos fornecer o instrumental necessário para a desconstrução. Não é por acaso que os trabalhos com ênfase na desconstrução, nas áreas das Ciências Sociais ou das Artes, acabam por manejar um grande arcabouço histórico.

A desconstrução procura demonstrar e desessencializar um determinado constructo social, mostrando que ele não é inevitável. Uma vez que o regime de representação racializado, produtor de estereótipos, age justamente em direção à essencialização, a desconstrução parece ser o caminho mais adequado para enfrentar essas representações enviesadas, pois pode desvelar os meios pelos quais foram construídas e apontar possibilidades de ressignificação a partir de novas montagens.

Anos 90, Porto Alegre, v. 25, n. 48, p. 351-377, dez. 2018 
Stuart Hall buscou compreender estratégias contra-hegemônicas, as quais chamou de contra estratégia ${ }^{16}$, que objetivam contestar os estereótipos e desativar as visualidades racializadas. As abordagens possíveis identificadas pelo autor são, primeiramente, abordagens que atuam nas relações da imagem, como a criação de imagens positivas. A segunda abordagem é a que atua nas políticas da imagem, que consiste na ação de desmontar as imagens. Para o autor, a segunda abordagem pode promover estratégias mais apropriadas, embora também não ofereça quaisquer garantias de sucesso.

Sobre a primeira abordagem, o desenvolvimento de representações positivas dos grupos que são vítimas das representações estereotipadas é uma das primeiras estratégias utilizadas pelos movimentos antirracistas. Como explica Hall (1997), a chamada representação positiva é quando se intervém estabelecendo uma imagem oposta à representação simplificada e portadora de qualidades negativas, numa tentativa de reversão ou inversão do estereótipo. Essa foi uma das principais estratégias de movimentos como Négritude, na década de 1940, e Black is Beautiful, na década de 1960, cujo objetivo principal era a afirmação identitária positiva da estética negra.

Em The Spectacle of the 'Other' (1997), Hall subdivide em duas práticas as estratégias que partem de um sujeito centralizado. Essas são as abordagens relativas às relações de representação, que o autor chamou também de Trans-coding, ou transcodificar - prática de partir de um significado dado (re)apropriando-se para dar um novo sentido. A primeira é o que o autor chama de "reverter os estereótipos” e a segunda trata-se da criação de imagens positivas para fazer frente às negativas ${ }^{17}$.

Nos termos de Mbembe (2010, p. 2), esses esforços de consciência de si e emancipação da representação por vezes acarretaram em duas formas de historicismo: "A primeira delas, carregada de instrumentalismo e oportunismo político, poderia ser designada de afro-radicalismo; a segunda consiste no peso da metafísica da diferença (nativismo)". Em que se pese a impossibilidade de se fixar sentidos, todas essas iniciativas foram importantes para alargar o leque de identificações e são referências para movimentos antirracistas contemporâneos. 
A terceira contra estratégia tenta sair do sistema binário atuando no próprio sistema representativo em sua formação, complexidades e ambivalências. São contra estratégias que tentam minar a representação de seu próprio interior. Trata-se de um desmontar de imagens, corpos e identidades. Essas estratégias propõem uma verdadeira incursão no interior da imagem; tal qual a complexidade que envolve a construção do estereótipo, sua desconstrução é ainda mais complicada, pois presta-se a adentrar os significados encerrados nas imagens estereotipadas, desengendrando-as de tal maneira a revertê-las contra si mesmas. É um trabalho complexo, visto que envolve questionar e expor o próprio funcionamento de representação. A construção do estereótipo é exposta por meio da desmontagem, que revela as formas com que uma certa noção foi naturalizada. A política da imagem envolve a desconstrução e a conseguinte desnaturalização de significados, o que propicia o surgimento do que Derrida chama de differance (diferância ou diferência), que é uma diferença não pautada pela dualidade, colocando em causa o conceito de origem, já que a fonte do significado ou um fim do diferimento não são identificáveis.

Portanto, ela está mais preocupada em compreender e expor as formas de representação racial do que com a produção de novos conteúdos ou novas formas, não correndo o risco de repetir fantasias racistas, mas direcionando-se para uma prática de desconstrução. $\mathrm{E}$, nessa prática, o corpo, que abrigou os valores racistas, é figura central, pois é no corpo que o olhar racializado trabalha para fixar estereótipos $^{18}$. Como afirma Hall (1997, p. 274), “[...] ao invés de evitar a imagem do corpo negro, porque ele tem sido tão apreendido nas complexidades do poder e subordinado na representação, essa estratégia positivamente pega o corpo como principal aspecto de sua estratégia representacional, tentando fazer com que os estereótipos funcionem contra eles mesmos”.

O discurso racial produziu uma economia de visualidade e, ao mesmo tempo, de invisibilidade. Esse discurso embalou e embala políticas, éticas e estéticas que ao longo da história exerceram suas consequências diretas no cotidiano de milhões de pessoas. $\mathrm{O}$ que esse discurso mostrou e escondeu é a base do regime de visualidade que serve de fonte para artistas que desenvolvem uma crítica 
pós-colonial em seus trabalhos. Como afirma Gonzaléz (2008, p. 4), "[...] o discurso racial produz o sujeito que supostamente ele descreve" e essa é uma questão central, pois desengendrar esse discurso que é baseado na visualidade é um dos objetivos de muitos artistas visuais na atualidade.

Os trabalhos de artistas como Rosana Paulino, Isaac Julien, Carrie Mae Weems, Paulo Nazareth, Adriana Varejão, John Akomfrah, Sidney Amaral, coletivo Frente 3 de Fevereiro, entre tantos outros artistas contemporâneos, se voltam para o passado para interrogar o presente, mostrando como há práticas e desigualdades herdadas que servem ainda para a manutenção da mesma ordem. Como explica Gonzaléz, práticas que reivindicam direitos ontológicos, tais como o direito de existir, o direito a um território, o direito à história e à imagem.

A referência à representação do passado tem um propósito crítico de interrogar às formas e meios com os quais foi construído o regime visual racializado, portanto, não devemos confundir essa abordagem histórica com uma forma conservadora do pós-modernismo, que se utilizava de signos históricos por questões de pastiche estilístico (GONZALÉZ, 2008, p. 19). Esses artistas desenvolvem contra estratégias, que atuam no próprio funcionamento da imagem e que buscam dotá-las de ressignificações. Como explica a artista Rosana Paulino sobre sua obra (2016):

Em meu trabalho penso no uso da imagem de uma maneira meio 'homeopática', se posso dizer assim. Como na homeopatia, que tem o princípio do 'semelhante cura semelhante', penso que no campo das imagens a coisa ocorre mais ou menos da mesma maneira: imagem 'cura' imagem, ou seja, os danos causados por um imaginário nefasto só podem ser transformados através de outras imagens que instiguem, que façam pensar, que mudem ideias estabelecidas no senso comum. Portanto, ressignificar estas imagens é parte importante de meu processo de trabalho.

O racismo foi possível graças à forma como se foi perpetrando no regime de visualidade. Esse regime instaurou uma determinada 
hierarquia de valores, que também eram valores estéticos. Em outras palavras, o racismo foi sustentado por indícios visuais ao mesmo tempo em que delineou a visualidade que o justificou e que colonizou. Como vimos, a questão racial encontra nas questões das visualidades uma importante encruzilhada e pode fornecer crucial contribuição para os estudos das imagens, não sendo uma questão de policiamento das mídias, de simples derrubada de monumentos ou aniquilamento dos vestígios do passado colonial. Como adverte Nietzsche (2003), a história deve servir à vida, enquanto história monumental ela pode servir de inspiração, mas perde função quando sua monumentalidade imobiliza o homem. Esse monumento que mais cria sombra do que abre horizonte, pode cair. No entanto, a mesma fórmula funciona para a história crítica. Enquanto crítica que abre caminhos, ela é bem-vinda e necessária. Enquanto crítica que destrói ou apaga o caminho percorrido, deve ser evitada. As imagens que nos trouxeram até aqui não podem e nem devem ser aniquiladas, mas algumas não devem ser reiteradas caso queiramos mudanças de trajetória. As imagerias racistas são um exemplo das imagens que devemos deixar ficar no passado caso desejemos visualizar no horizonte um outro regime representacional. Urge a produção de imagens ativas de reinvenção. Precisamos de imagens que apontem outros horizontes possíveis.

\section{ON THE RACIALIZED REGIME OF VISUALITY}

\section{AND THE VIOLENCE OF RACIST IMAGERY:}

\section{NOTES FOR THE IMAGE STUDIES}

Abstract: This article aims to investigate about the ways in which representation produced by images work, especially on the racist historical representation. Therefore, we questioned the so-called "transparency" of the image and interrogate the violent aspect of the racist imagery, as well as possibilities of deconstruction of this racialized visuality.

Keywords: Image studies. History of images. Racialized regime of visuality. Racist imagery. 
Sobre o regime de visualidade racializado e a violência da imageria...

\section{Notas}

${ }^{1}$ Mais usado no sentido técnico de produção de imagem como Medical imaging, Digital Imaging, Radar Imaging.

${ }^{2}$ É uma noção que eu desenvolvi de alguns anos para cá no âmbito do trabalho dos seminários da EHESS para tentar caracterizar particularmente, a partir dos instrumentos tradicionais da História da Arte, a produtividade das formas industriais ou das indústrias culturais, que geram efetivamente corpus por vezes muito importantes, como a iconografia do Che [Guevara], que nós estudamos [foi tema durante ambos de seus seminários no ano acadêmico 2014-2015], e que são grupos iconográficos especialmente difíceis. Com base nessa evidência, nós precisamos de meios de análise um tanto particulares, por isso a imagerie é um modo de tentar responder aos problemas específicos postos pelos usos populares e comuns da imagem, principalmente em suas formas industriais. O que distinguiria a fundo a imagerie de uma iconografia, portanto um grupo qualquer de imagens, é a constatação de que certos grupos de imagens são produtivos, ou seja, tornam-se virais e se desenvolvem ao longo do tempo, segundo princípios de ordem econômica. O fato da adaptação, de fazer um filme a partir de um romance - peguemos o exemplo de Harry Potter ou qualquer outro exemplo -, pode ser visto como um mecanismo econômico, que é um mecanismo de oportunismo econômico muito básico. A partir desse mecanismo, a difusão, cada vez mais importante, de referências culturais produz algo de particular, tanto a nível iconográfico quanto a nível cultural, isso quer dizer que, no fundo, e mais uma vez, eu vou utilizar a noção de Marin, essas iconografias, e, por conseguinte, essas imageries são produtivas e têm por característica não criar uma nova realidade, mas fazer parte da História. Tomemos um exemplo simples: o Papai Noel. Nós sabemos que ele não existe - triste notícia - e ainda assim, quando eu digo "o Papai Noel”, vocês sabem a que faço referência. Portanto, é um personagem de ficção, mas é também uma presença cultural, e uma presença cultural é algo que quase existe, que tem uma forma de existência, não é exatamente uma existência real, mas que é, tomo o termo de Marin, presente. E essa presença é suficiente para gerar uma produtividade iconográfica, e, portanto, nesse caso, a iconografia se torna a verificação da presença. Há, assim, uma forma autorreferencial que se desenvolve entre a imagem e seu referente, não mais o referente semiótico, mas sim o referente cultural, e essa forma se instala como uma referência no sentido cultural. Com esse exemplo, vemos como a imagem produz coisas ou quasi-coisas. A questão ainda mais importante: a produtividade imaginária. Pode-se constatar que não há diferença entre, de um lado, as formas ficcionais e, de outro, as formas reais. $\mathrm{Na}$ verdade, você e eu,

Anos 90, Porto Alegre, v. 25, n. 48, p. 351-377, dez. 2018 
enquanto grande público destinatário de todas essas representações, não temos meios de verificar quais são as formas realmente existentes e as que vêm de uma construção imaginária. Tudo isto é definido aproximadamente no mesmo plano e segue os mesmos caminhos e os mesmos canais de produção. Aqui chegamos a um problema muito importante e que retorna, de outra maneira, à questão da performance das imagens: como elas instalam referentes autônomos? É a lição da imageria. E se são as imagens que produzem algo, o que produzem? Elas produzem essencialmente outras imagens. Por isso que, finalmente, as imagens chegam a instalar presenças. Essa noção é bastante diferente das reflexões de Warburg sobre o pathosformel, que, do meu ponto de vista, são muito mais formalistas para descrever operações que são essencialmente de funcionamentos sociais. A partir de tudo isso que acabo de descrever sobre o funcionamento da imagerie, e que são efeitos de reflexões minhas, concluo que ela é construída pelo destinatário, com interpretações de sinais e que, portanto, estamos em um universo que é o da imagem social. Para mim, essa escala é a mais correta para observar, não as formas de arte, mas os usos comuns das imagens. Em relação a isso, nesse contexto particular, as ferramentas de Warburg me parecem bem menos operantes" (GUNTHERT apud DOSSIN; LEAL, 2015, p. 98-99).

${ }^{3} \mathrm{O}$ Museu Afro-Brasil em São Paulo guarda em seu acervo dois tocheiros.

${ }^{4}$ Referência ao que o sociólogo Robert K. Merton chama de self-fulfilling prophecy (algo como Profecia Autorrealizável), que, se ampliarmos para o campo social, se refere à realização do que foi preconcebido, pois o grupo discriminador identifica na realidade apenas aquilo que foi preparado para ver e ao grupo discriminado sobram poucas imagens de autoidentificações fora daqueles considerados desviantes e causadores do estigma. Segundo Merton, "a profecia autorrealizável é, começo, uma falsa definição da situação, que evoca um novo comportamento, fazendo com que a falsa concepção se torne verdadeira [...] perpetuando um reino de erros.” (MERTON, Robert. Social Theory and Social Structure. New York: Free Press, 1968. p. 477).

${ }^{5}$ Neologismo usado por Paul Ricouer para se referir às operações de representação do passado histórico. O conceito lida com o referente, as relações do conhecimento histórico com a realidade, as representações e as dimensões narrativas da escrita da história. Condensa expectativas, experiências e intencionalidades nas reconstruções do passado.

${ }^{6}$ A revista Semana Ilustrada, que funcionou de dezembro de 1860 até abril de 1876, tinha oito páginas, com textos e ilustrações, foi idealizada pelo alemão Henrique Fleiuss, que acabou realizando uma revolução gráfica na imprensa nacional da segunda metade do século XIX, estabelecendo novos parâmetros

Anos 90, Porto Alegre, v. 25, n. 48, p. 351-377, dez. 2018 
de qualidade editorial. Como explica Pereira (2015, p. 11), “[...] o Dr. Semana cultivava relações com a elite e circulava livremente pela corte, o que lhe oferecia oportunidades para observar condutas, acompanhar fatos e comentá-los com seu leal companheiro, o moleque. Caricaturados exaustivamente na revista, muitas das capas da edição traziam as andanças da dupla pelos cenários públicos da corte”.

${ }^{7}$ Cf. SECRETARIA Especial de Comunicação Social Semana. Ilustrada: história de uma inovação editorial. Rio de Janeiro: Prefeitura da Cidade do Rio de Janeiro, 2007. 102 p.

${ }^{8}$ SANTIANO-ALMEIDA, Manoel Mourivaldo; CAMBRAIA, César Nardelli. As molecagens fizeram o "moleque": a aventura da palavra de origem africana. Revista Língua Portuguesa, maio 2014. Disponível em: <http://revistalingua. com.br/textos/103/as-molecagens-fizeram-o-moleque-311366-1.asp>. Acesso em: 7 mar. 2016.

${ }^{9}$ Embora o embate entre iconoclastas e iconófilos seja insuficiente para se compreender os atentados de 2015 em Paris, a questão da imagem e sua potência podem contribuir para se pensar questões de estereótipos, representabilidade e violência.

${ }^{10}$ A violência do visível está diretamente ligada ao destino político das emoções. No entanto, a violência problemática não reside na imagem isoladamente: "Não é o conteúdo da imagem que torna sua violência problemática, porque este conteúdo pode ser indiferentemente cruel, provocador ou pacífico sem que a imagem faça violência ao pensamento e o leve à destruição. Há visibilidades que personificam um discurso, é sempre o discurso do mestre. A partir de então, o visível doutrina e incorpora o espectador para a visibilidade da personificação do corpo, que não é outro senão o corpo do discurso que o sustenta. $\mathrm{O}$ discurso do mestre submete o olhar ao visível e o envolve em assentimento" (MONDZAIN, 2002, p. 69).

${ }^{11}$ Poder, segundo o autor, é a condição de poder exercer ação sobre algo ou alguém. Como diz o autor: "O que dizemos quando dizemos "poder"? Poder é, antes de tudo, estar em situação de exercer uma ação sobre algo ou alguém; ou não exercer, mas sim ter a potência, ter essa força de fazer ou atuar. Poder, no sentido mais vulgar e geral, é ser capaz de força, ter - e tem-se que insistir nessa propriedade - uma reserva de força que não se gasta mas que se põe em estado de gastar-se. Mas, o que é então uma força que não se manifesta, que não se exerce? Como afirmou Pascal, uma força semelhante é apenas dona de suas ações externas. Assim, o poder é potência, além disso, recuperação dele como coerção obrigatório, gerando deveres como lei. Nesse sentido, poder é instituir como lei a potência mesma concebida como possibilidade e capacidade de força.

Anos 90, Porto Alegre, v. 25, n. 48, p. 351-377, dez. 2018 
E esse é o ponto onde a representação cumpre seu papel, como é ao mesmo tempo meio da potência e seu fundamento. Daí a suposição geral subjacente a todo este trabalho, a saber, que o dispositivo representativo efetua a transformação da força em potência, da força em poder, e isso por duas vezes, por uma parte ao modalizar a força como potência e, por outra, ao valorizar a potência como estado legítimo e obrigatório, justificando-a." (MARIN, 2009, p. 138).

12 '[...] Representação narrativa é 'tomado' pelos repetitivos 'atos de fala' da promessa e da oblação nos quais o tempo passado é neutralizado pelo instante presente da representação icônica, ela mesma construída pela conjunção de duas sequências narrativas acerca do instante do milagre que não é mostrado mas contado pelo texto produzindo a representação" (MARIN, 1977, p. 48).

${ }^{13}$ Cf. MARIN, Louis. Opacité de la peinture: essais sur la représentation au Quattrocento. Paris: Éditions EHESS, 2006.

${ }^{14}$ Magritte esquematiza na pintura princípios da pintura ocidental de separação entre representação plástica, referência linguística (e esse do referente), assim como a indissociabilidade da equivalência entre semelhança e afirmação no laço representativo: "pouco importa, ainda aqui, o sentido em que está colocada à relação de representação, se a pintura é remetida ao visível, que a envolve, ou se ela cria, sozinha, um invisível que se assemelha" (FOUCAULT, Michel. Isto não é um cachimbo. Tradução Jorge Coli. São Paulo: Paz e Terra, 2004. p. 15).

${ }^{15}$ Desconstrução é uma noção que nos remete diretamente ao filósofo Jacques Derrida, que a utilizou pela primeira vez na introdução à tradução da Origem da Geometria, de E. Husserl, de 1962. A desconstrução não significa destruição, como se poderia pensar num primeiro momento. A desconstrução tem por método a desmontagem, ou seja, a decomposição dos elementos de um determinado conjunto do pensamento metafísico ocidental, que se desenvolveu a partir de relações binárias para estabelecer uma hierarquia de um termo sobre o outro. A desconstrução, assim, tem por função procurar compreender a construção de discursos e representações através do método de desmontagem. Essa concepção de desconstrução é bastante semelhante à contra estratégia de "desmontagem da imagem" no âmbito do regime de representação racializado, identificado por Hall. Segundo Campos Pedroso Junior (2010, p. 13), a proposta de desconstrução derridariana é "um procedimento de questionamento, de decomposição e de reorganização dos discursos até então empreendidos pela metafísica ocidental”, ou ainda, mais que um procedimento, pode ser entendida também como "[...] uma posição filosófica, uma estratégia política ou intelectual e um modo de leitura” (CULLER apud JUNIOR, 2010, p. 16). Por isso, a desconstrução "significou uma abertura revolucionária [...] como ideologia democrática e não preconceituosa” (JUNIOR, 2010, p. 20), sendo um

Anos 90, Porto Alegre, v. 25, n. 48, p. 351-377, dez. 2018 
"abre-alas" para o êxito de abordagens posteriores como os Estudos Culturais e os Estudos Pós-Coloniais.

${ }^{16}$ Contra estratégia é o termo utilizado por Stuart Hall sobretudo em seu texto The Spectacle of the 'Other' (HALL, Stuart. Representation: Cultural Representations and Signifying Practices. London: Sage; Open University, 1997) e guarda algumas semelhanças com o conceito de tática de Michel de Certeau. O termo contra estratégia é empregado para designar notadamente estratégias de resistência. Assim, uma vez contextualizadas as intenções contra hegemônicas dessas estratégias, é possível referir-se apenas ao termo estratégia.

${ }^{17}$ A primeira contra estratégia seria aquela própria da década de 1950, quando, por exemplo, em Hollywood, surge uma política integracionista. Essa política, apesar de algumas conquistas, custavam a assimilação de normas brancas de estilo, aparência e comportamento. Logo, com a luta pelos direitos civis que se estendem pela década de 1960, levou a uma valorização positiva das diferenças e a uma afirmação mais agressiva da identidade cultural da população afrodescendente. Exemplo da primeira estratégia seria a produção cinematográfica que ficou conhecida posteriormente como Blaxploitation. Esses filmes trouxeram um princípio de empoderamento com seus heróis negros, no entanto, como lembra Hall (1997, p. 272), “[...] não escapou das contradições da estrutura binária da representação racial". Os filmes da Blaxploitation, no ensejo de reverter o estereótipo do homem negro infantilizado e servil, acabaram por reforçar a imagem ligada à violência e ao sexo, ou seja, continuaram a atuar a partir de estereótipos. Para Hall, reverter um estereótipo não é necessariamente subvertê-lo, de forma que esses filmes acabaram também oferecendo uma imagem unilateral, apenas adicionando mais imagens estereotipadas ao repertório do regime racializado de representação.

A segunda contra estratégia consiste em substituir as imagens negativas por imagens positivas, gerando identificações raciais positivas. Esta inverte a posição binária "privilegiando o termo subordinado" (HALL, 1997, p. 272), ao celebrar a diversidade. Para Hall, essa contra estratégia problematiza e aumenta a variedade de representações racializadas, ampliando, assim, os sentidos de ser negro, mas também acaba reiterando a homogeneização das culturas não brancas. $\mathrm{O}$ autor pensa em exemplos como os da publicidade da United Colours of Benetton e as fotografias de David Bailey em Rethinking black representation (1988). Para o autor, apesar de alargar a gama de representação, as imagens positivas não conseguem deslocar as imagens negativas e, por conseguinte, minar o sistema binário de representação.

18 "Uma vez que as pessoas negras têm tão frequentemente sido fixadas, estereotipadas, pelo olhar [gaze] racializado, poderia ser tentador recusar as complexas

Anos 90, Porto Alegre, v. 25, n. 48, p. 351-377, dez. 2018 
emoções associadas ao "olhar" [looking]. Contudo, essa estratégia faz um jogo elaborado com o "olhar" [looking], esperando pela própria atenção "tornar estranho" - que é desfamiliarizá-lo, e assim tornar explícito o que é frequentemente escondido" (HALL, 1997, p. 274).

\section{Referências}

COLI, Jorge. Arte e pensamento. In: FLORES, Maria Bernardete Ramos; VILELA, Ana Lucia (Org.). Encantos da imagem: estâncias para a prática historiográfica entre história e arte. Florianópolis: Letras Contemporâneas, 2010.

DEVISSE, Jean; LABIB, Shuhi. A África nas relações intercontinentais. In: NIANE, Tamsir (Org.). História Geral da África: África entre os séculos XII e XVI. v. 4. São Paulo: Ática; Unesco, 1988.

DICIONÁRIO. Le Grand Robert de la Langue Française. Paris, 2001.

DOSSIN, Francielly; LEAL, Elisabete. Os estudos das imagens, segundo André Gunthert. ArtCultura, Uberlândia, v. 17, n. 31, p. 91-100, jul./dez. 2015.

FERREIRA, Aurélio Buarque de Holanda. Aurélio século XXI: o dicionário da língua portuguesa. Rio de Janeiro: Nova Fronteira, [1999].

FLORES, Maria Bernardete Ramos; MELO, Sabrina Fernandes. A libertação de Cam: discriminar para igualar. Sobre a questão racial brasileira In: RODRIGUES, Cristina; LUCA, Tania; GUIMARÃES, Valéria (Org.). Identidades brasileiras: composições e recomposições. São Paulo: Cultura Acadêmica, 2014.

GONZÁLEZ, Jennifer. Subject to display: reframing race in contemporary installation art. Cambridge; London: MIT Press, 2008.

HALL, Stuart (Org.). Representation. Cultural representation and cultural signifying practices. London; Thousand Oaks; New Delhi: Sage; Open University, 1997.

. The West and the Rest: Discourse and Power. In: HALL, Stuart; GIEBEN, Bram. Formations of Modernity. Cambrigde: Blackwell, 1995. p. 276-333. HOUAISS, Antônio; VILLAR, Mauro de Salles; FRANCO, Francisco Manoel de Mello. Dicionário Houaiss da língua portuguesa: com nova ortografia da língua portuguesa. Rio de Janeiro: Objetiva, 2009.

JUNIOR, Neurivaldo Campos Pedroso. Jacques Derrida e a desconstrução: uma introdução. Revista Encontros de Vista, 5. ed., jan./jun. 2010. Disponível em: 
Sobre o regime de visualidade racializado e a violência da imageria...

<http://encontrosdevista.com.br/Artigos/Neurivaldo_Junior_Derrida_e_a_desconstrucao_uma_introducao_final.pdf $>$. Acesso em: 16 fev. 2016.

LITLLE, William. The shorter oxford English dictionary: on historical principles. Oxford: Clarendon Press, 1970.

MARIN, Louis. Du fantastique dans l'art contemporain: sur quelques aspects théoriques. In: SEIXO, Maria Alzira. O Fantástico na arte contemporânea: actes du colloque de févr./mars 1987. Lisbonne: Fondation Calouste-Gulbenkian, 1992. p. 105-114.

. Interview: Louis Marin. Diacritics, v. 7, n. 2, p. 44-53, 1977.

. Opacite de la peinture. Essais sur la Representation au Quattrocento. Paris: Editions de l'EHESS, 2006.

. Poder, representación, imagen. Prismas, v. 13, n. 2, p. 135-156, 2009.

. Transparance et opacité de la peiture... Du moi. In: FORTUNATI, Vita (Ed.). Bologna, la cultura italiana e le letterature straniere moderne. Bologna: Longo Editore, 1992. p. 123-130.

MBEMBE, Achille. Crítica da razão negra. Tradução Marta Lança. Lisboa: Antígona, 2014.

MENESES, Ulpiano Bezerra. Fontes Visuais, Cultura Visual e História Visual. Balanço provisório, propostas cautelares. Revista Brasileira de História, São Paulo, v. 23, n. 45, p. 11-36, 2003. Disponível em: <http://scielo.br/pdf/rbh/ v23n45/16519.pdf>. Acesso em: 10 fev. 2012.

MONDZAIN, Marie-José. L'image peut-elle tuer? Le temps d'une question. Bayard: Paris, 2002.

MONDZAIN, Marie-José. Nous ne nous en sortirons que par une révolution politique. Entrevista a Antoine Perroud. Mediapart, 11 jan. 2015. Disponível em: $\langle$ http://mediapart.fr/journal/culture-idees/110115/marie-jose-mondzain-nous-nenous-en-sortirons-que-par-une-revolution-politique>. Acesso em: 27 mar. 2015.

NIETZSCHE, Friedrich. Segunda consideração intempestiva: da utilidade e desvantagem da história para a vida. Tradução Marco Antonio Casanova. Rio de Janeiro: Relume Dumará, 2003.

PAULINO, Rosana. Nossa herança africana: entrevista com Rosana Paulina. Revista Technography: arte e reflexão, n. 3, 2016. Disponível em: <http://tecnography.com/\#!blank/rmpxz>. Acesso em: 9 mar. 2016.

PENKALA, Ana Paula. O mal-estar na visualização e outras estéticas: da imageria do audiovisual pós-moderno. Tese (Doutorado em Comunicação)-Programa de 
Pós-Graduação em Comunicação e Informação, Universidade Federal do Rio Grande do Sul, Porto Alegre, 2011.

PEREIRA, Renan Rivaben. Semana Ilustrada, o Moleque e o Dr. Semana: imprensa, cidade e humor no Rio de Janeiro do $2^{\underline{a}}$ Reinado. Dissertação (Mestrado em Letras)- Faculdade de Ciências e Letras de Assis, Universidade Estadual Paulista, São Paulo, 2015.

RICOEUR, Paul. A memória, a história, o esquecimento. Campinas: Unicamp, 2007.

ROBERT, Paul. Le nouveau petit Robert: dictionnaire alphabetique et analogique de la langue française. Nouvelle ed. Paris: Dictionnaires Le Robert, 1993.

SANTIANO-ALMEIDA, Manoel Mourivaldo; CAMBRAIA, César Nardelli. As molecagens fizeram o "moleque": a aventura da palavra de origem africana. Revista Língua Portuguesa, maio 2014. Disponível em: <http://revistalingua. com.br/textos/103/as-molecagens-fizeram-o-moleque-311366-1.asp>. Acesso em: 7 mar. 2016.

SECRETARIA Especial de Comunicação Social Semana. Ilustrada: história de uma inovação editorial. Rio de Janeiro: Prefeitura da Cidade do Rio de Janeiro, 2007. $102 \mathrm{p}$.

STOLS, Eddy. Aparências, imagens e metamorfoses dos africanos na pintura e na escultura flamenga e holandesa (sécs. XV-XVII). In: FURTADO, Júnia Ferreira (Org.). Sons, formas, cores e movimentos na modernidade atlântica: Europa, Américas e África. São Paulo: Annablume; Belo Horizonte: FAPEMIG, PPGH-UFMG, 2008.

WEBSTER'S encyclopedic unabridged dictionary of the english language. New York: Gramercy, 1994.

Recebido em: 24/03/2018

Aprovado em: 15/08/2018 
